\title{
Research on Search Method of Potential Sliding Surface of Rock Slope with Embedded Structural Plane
}

\author{
Aijun Yao, ${ }^{1}$ Jian Lu $\mathbb{D}^{2}{ }^{2}$ Zhizhou Tian, ${ }^{3}$ and Yanyan $\mathrm{Li}^{1}$ \\ ${ }^{1}$ The Key Laboratory of Urban Security and Disaster Engineering, Ministry of Education, Beijing University of Technology, \\ Beijing 100124, China \\ ${ }^{2}$ Road Safety Research Center, Research Institute of Highway Ministry of Transport, Beijing 100088, China \\ ${ }^{3}$ Beijing Municipal Construction Group Co., Ltd., Beijing 100045, China \\ Correspondence should be addressed to Jian Lu; lj_beyond@sina.com
}

Received 6 May 2021; Accepted 9 September 2021; Published 12 October 2021

Academic Editor: Daniele Perrone

Copyright (C) 2021 Aijun Yao et al. This is an open access article distributed under the Creative Commons Attribution License, which permits unrestricted use, distribution, and reproduction in any medium, provided the original work is properly cited.

\begin{abstract}
Slope stability has been a key issue in the field of geotechnical engineering. Determining the potential sliding surface of a slope is an important link in evaluating the stability of the slope. For rock slope with embedded structural plane, the potential sliding surface is greatly affected by the embedded structural plane. When determining the potential sliding surface, the influence of the position of the embedded structural plane should be considered. According to the distribution characteristics of the embedded structural plane of the rock slope, the structural plane in rock slope is divided into two types: (1) front embedded and (2) rear embedded structural plane. Considering the influence of two types of structural planes, a search method for potential sliding surfaces of rock slope is proposed combined with the finite random tracking method. The location of the sliding surface is controlled through the cut-in point, cut-out point, and arc height so that the range of search variables does not need empirical assumption. An engineering example is used to verify the search method. The results show that the method could accurately obtain the potential sliding surface of the rock slope with embedded structural plane, which proves the effectiveness of the search method.
\end{abstract}

\section{Introduction}

In the process of engineering project construction, different types of slope engineering are often encountered, such as high and steep slopes formed by open-pit mining, high excavation, and fill slopes formed during the construction of power facilities. The stability of these complex slopes is related to the safety of people and project construction. If the slope is unstable, it will form landslides and collapses, causing serious consequences. Therefore, the evaluation of slope stability has become a hot issue. The analysis and evaluation of slope stability mainly include two aspects. The first aspect is the search for the position of the potential sliding surface in a slope, and the second aspect is the calculation of the stability coefficient along the potential sliding surface in the slope. There is a close relationship between the determination of the position of the potential sliding surface of the slope and the calculation of the slope stability coefficient. The calculation of the slope stability coefficient should be based on the sliding surface obtained by random search, and the potential sliding surface of the slope is determined by comparing the safety factors of sliding surfaces obtained from all searches. Among the calculation methods of slope stability, the most commonly used method is the limit equilibrium method, including Spencer method $[1,2]$, Bishop method [3, 4], Janbu method, transfer coefficient method, Morgenstern-Price method, Sarma method, as well as various methods to improve and optimize the above methods [5-8]. Tang et al. [9] considered the influence of the locked section in the rock slope and analyzed the dissipated power inside the slope. In addition, Tang et al. [9] deduced the calculation formula of the safety factor of the rock slope with the locked section in the shear failure mode, according to Mohr-Coulomb associated flow law, which 
provided a new idea for the stability evaluation of this kind of slope. Chen et al. [10] introduced the equivalent influence angle $\theta_{e}$ to evaluate the different contributions of the cohesion $c$ and the internal friction angle $\varphi$ to slope stability. The influence of the different weight and height of the slope on the equivalent influence angle $\theta_{e}$ was analyzed, and an improved slope stability calculation method was proposed based on the double strength reduction method, which improved the rationality of the calculation method.

The search methods of potential sliding surface include the pattern search method [11], mathematical programming method $[12,13]$, random search method [14], particle swarm optimization algorithm $[15,16]$, and genetic algorithm [17]. For the random search method, Wan et al. [18] combined the simplified 3D-Spencer method and proposed a slope stability evaluation method considering seismic force, which was verified by an engineering application. Although the pattern search method, random search method, particle swarm optimization algorithm, and genetic algorithm have strong global search capabilities, they have the characteristics of a large amount of calculation. The mathematical programming methods such as simplex optimization algorithms have strong local search capabilities, but they have the disadvantage of insufficient global search capabilities.

Because the structure of rock slope is very complex, its stability depends on the characteristics of various structural planes in the slope [19]. Therefore, the influence of structural planes needs to be considered when searching sliding surfaces. This research considers the control effect of embedded structural plane on the distribution of potential sliding surfaces and proposes a finite random tracking method which could quickly and accurately search the potential sliding surface in rock slope. An engineering example is used to verify the practicability of the proposed method.

\section{Characteristics of Embedded Structural Planes in Rock Slopes}

The embedded structural plane within a slope refers to the discontinuity which strongly controls the stability of the slope. Once the slope becomes unstable, the slope body will slide along the embedded structural plane. There are mainly two types of embedded structural planes in a slope: (1) front embedded structural plane and (2) rear embedded structural plane.

The front embedded structural plane is located at the front edge or foot of a slope (Figure 1). It often refers to rock discontinuity such as joint, fault, or weak layer. The dip angle of the front embedded structural plane is often gentle, and the shear strength is low. If the slope becomes unstable, the front embedded structural plane will be the main control structural plane, and the slope body will be cut out at a certain point of the structural plane, as shown in Figure 1.

The characteristics of the rear embedded structural plane are shown in Figure 2. Slope failure along this structural plane is more common. The main reason is that there are structural planes such as tensile cracks or high angle joints or fissures in the rear edge of the slope, which play a controlling role for the slope stability. This will facilitate the instability of the slope, especially when the discontinuity is filled with water. Once the stability of the slope exceeds the limit state, the slope body will slide along this structural plane.

\section{Finite Random Search Method for Potential Sliding Surfaces}

3.1. Recognition and Analysis of Slope Geometry. In actual engineering, in addition to single-stage slopes, there are also multistage slopes or multistep slopes. Multistep slopes mainly occur during the formation of slopes by stepwise grading or stepwise backfilling. For this kind of slope, it is difficult to determine the position of the potential sliding surface. In the past, civil engineers often mapped the search range of the cut-in point and cut-out point of the slope on the interval ranging from 0 to 1 ; that is, the global slope line was used as the search scope of cut-in point and cut-out point. This will result in that only one arc sliding surface with the smallest safety factor could be obtained, and it is often falling into the local minimum value, as shown in the shaded part in Figure 3. However, the position of the potential sliding surface $S E$ of the slope cannot be determined, and the stability coefficient of the entire slope will be unknown.

In order to avoid the occurrence of minimum values, the geometric model of the slope is discretized into multiple nodes or line segments. This research assumes that the slope has a complex stratum, and the slope body is a heterogeneous. For example, as shown in Figure 4, the slope is composed of three stratigraphic regions with different lithologies, namely, region I, region II, and region III. Region $\mathrm{I}$ is distinguished by three geometrical boundary lines and a formation boundary line composed by four control points including points 7, 6, 9, and 8 with counterclockwise order. Region II is divided by five geometrical boundary lines and two formation boundary lines controlled by seven control points $(6,5,4,3,2,10$, and 9$)$. Region III is controlled by five points $(2,1,12,11$, and 10$)$ constituting four boundary lines and a stratum boundary line.

The shape of the slope surface is irregular (Figure 4). In order to facilitate the program design, the slope surface line is also discretized. As shown in Figure 4, the slope surface line is discretized into seven line segments $\left(L_{7}, L_{6}, \ldots, L_{1}\right)$ controlled by eight points $(8,7,6, \ldots, 1)$. The same strategy is adopted for the groundwater level line inside the slope (Figure 4), and the groundwater level line is discretely divided into six lines controlled by seven points $([1],[2], \ldots$, [7]).

In Figure 4, it is assumed that the potential sliding surface is an arc sliding surface, which is represented by an arc composed of three points: cut-in point $S$, midpoint of sliding surface $T$, and cut-out point $E$. $q_{1}$ and $q_{2}$ are the area load acting on the top of the slope. The area load is mainly generated by the accumulated load on the top of the slope 


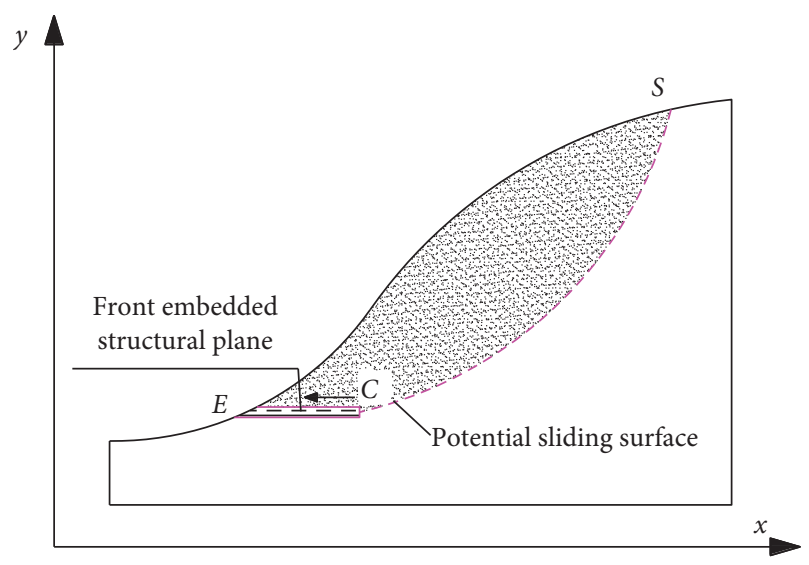

Figure 1: Characteristics of front embedded structural plane.

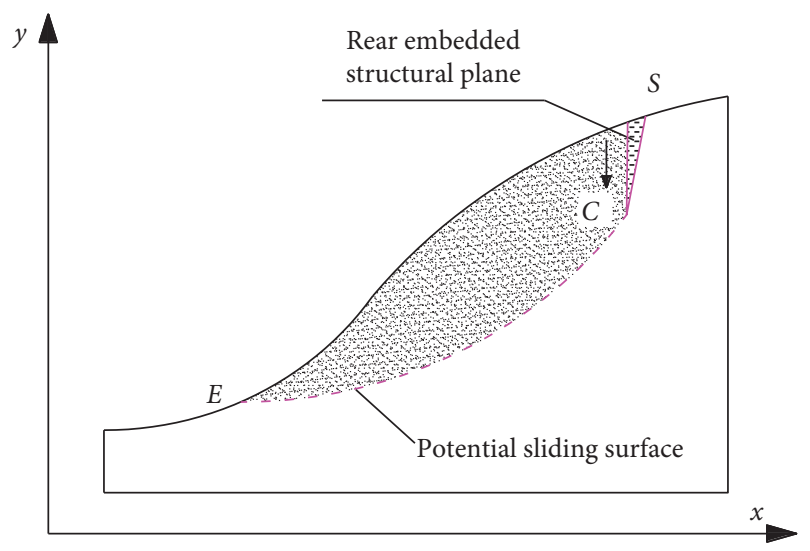

FIgURE 2: Characteristics of rear embedded structural plane.

and the self-weight of the building or structure. $F_{1}, F_{2}$, and $F_{3}$ are the concentrated forces acting on the free surface of the slope, which are mainly caused by the reinforcement of anchor rods or cables. The generation of the potential sliding surface in the slope is described in detail in the next section.

3.2. Finite Random Tracking Method. It is necessary to find all potential sliding surface of the slope before finding the minimum value of the safety factor in all areas of the slope. The main idea of this paper is to construct the sliding surface analytical formula by using the cut-in point $S$, cut-out point $E$, and midpoint of sliding surface $T$ and to obtain the expression of the center coordinates and radius of the sliding surface. Then, according to the search range of cut-in point $S$, cut-out point $E$, and midpoint of sliding surface $T$, all potential sliding surfaces of the slope are searched, and the safety factor of the sliding surface is calculated, respectively, and finally the minimum value of the safety factor of all areas is found. Finally, the potential sliding surface of the slope is found.

Since the slope surface line is represented by multiline segments controlled by several discrete points, the search range of the cut-in point and cut-out point could be set in sections. As shown in Figure 4, the slope surface line of the slope has seven line segments $\left(L_{7}, L_{6}, \ldots, L_{1}\right)$. If the position

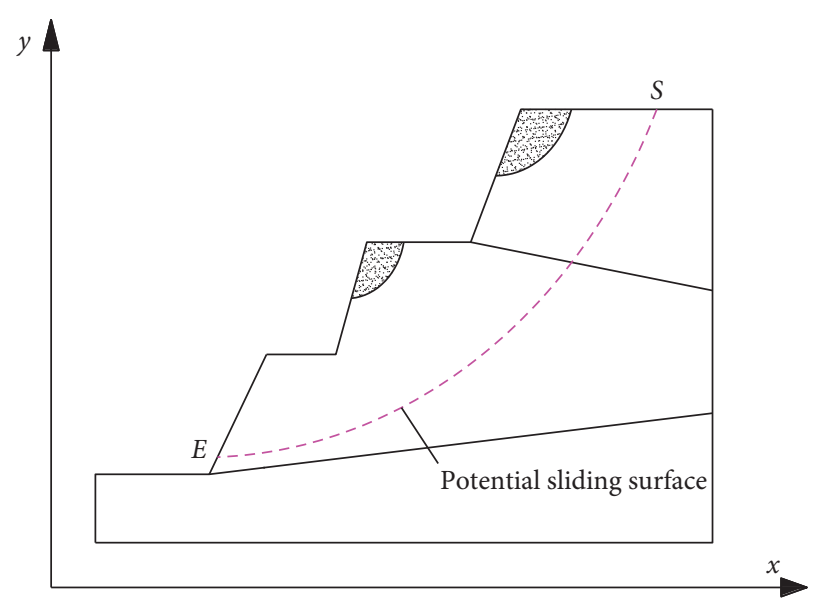

FIGURE 3: Schematic diagram of slope falling into local minimum.

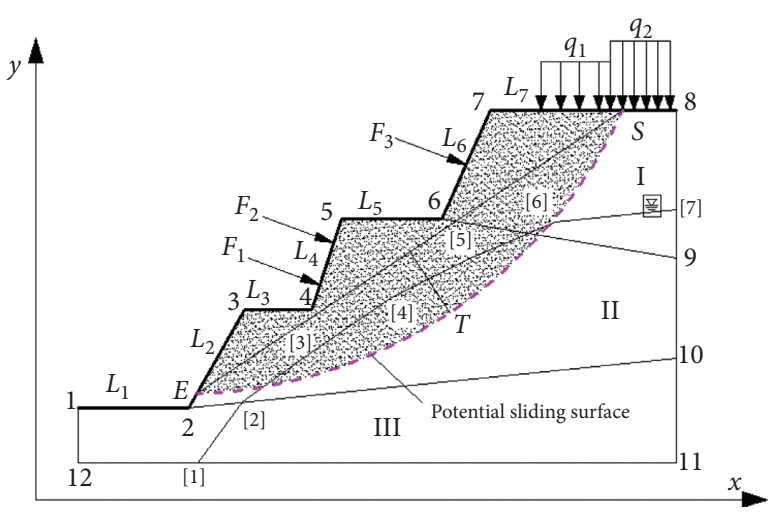

FIGURE 4: Discrete schematic diagram of the slope geometric model.

of the cut-in point is located on $L_{7}$, the position of the cutout point could be located at any position of the line segments $L_{6}, L_{5}, L_{4}, L_{3}, L_{2}$, or $L_{1}$. One by one search can determine 6 local minima. According to the permutation and combination, 21 local minimum values can be determined.

In order to simplify the construction process of the potential sliding surface of the slope and to facilitate the calculation of the program, the potential sliding surface of the slope is assumed to be an arc sliding surface. The arc can be determined by three points on the circle. Assuming that the cut-in point is on $L_{7}$ and the search range of the cut-out point is on $L_{2}$, if the position of another point $T$ on the arc could be determined, then the function analytical form of the arc STE $y=f(x)$ can be obtained. The expressions of the center and radius of the circle can also be obtained.

Next, according to the cut-in point $S$, cut-out point $E$, and midpoint of sliding surface $T$, the arc analytical formula, center coordinates, and radius expressions are deduced. Supposing that the coordinates of the three points on the arc are $S\left(X_{S}, Y_{S}\right), T\left(X_{T}, Y_{T}\right)$, and $E\left(X_{E}, Y_{E}\right)$, the sliding surface of the arc is expressed by 


$$
\left|\begin{array}{cccc}
x^{2}+y^{2} & x & y & 1 \\
X_{S i}^{2}+Y_{S i}^{2} & X_{S i} & Y_{S i} & 1 \\
X_{E i}^{2}+Y_{E i}^{2} & X_{E i} & Y_{E i} & 1 \\
X_{T l}^{2}+Y_{T l}^{2} & X_{T l} & Y_{T l} & 1
\end{array}\right|=0
$$

The analytical formula is

$$
y=\frac{c}{2 a}+\sqrt{-x^{2}+\frac{b}{a} x+\frac{c^{2}}{4 a^{2}}+\frac{d}{a}}\left(X_{E} \leq x \leq X_{S}\right),
$$

where $a, b, c$, and $d$ are the intermediate parameters as follows:

$$
\begin{aligned}
& a=X_{S} Y_{T}+Y_{S} X_{E}+X_{T} Y_{E}-X_{E} Y_{T}-Y_{S} X_{T}-X_{S} Y_{E}, \\
& b=\left(X_{S}^{2}+Y_{S}^{2}\right)\left(Y_{T}-Y_{E}\right)+\left(X_{T}^{2}+Y_{T}^{2}\right)\left(Y_{E}-Y_{S}\right)+\left(X_{E}^{2}+Y_{E}^{2}\right)\left(Y_{S}-Y_{T}\right), \\
& c=\left(X_{S}^{2}+Y_{S}^{2}\right)\left(X_{E}-X_{T}\right)+\left(X_{T}^{2}+Y_{T}^{2}\right)\left(X_{S}-X_{E}\right)+\left(X_{E}^{2}+Y_{E}^{2}\right)\left(X_{T}-X_{S}\right), \\
& d=\left(X_{S}^{2}+Y_{S}^{2}\right)\left(X_{T} Y_{E}-X_{E} Y_{T}\right)+\left(X_{T}^{2}+Y_{T}^{2}\right)\left(X_{E} Y_{S}-X_{S} Y_{E}\right)+\left(X_{E}^{2}+Y_{E}^{2}\right)\left(X_{S} Y_{T}-X_{T} Y_{S}\right) .
\end{aligned}
$$

The center of the sliding circle $C\left(X_{c}, Y_{c}\right)$ and the radius $R$ where $e, f$, and $g$ are the intermediate parameters as follows: can be obtained by

$$
\left\{\begin{array}{l}
X_{C}=\frac{e}{g} \\
Y_{C}=\frac{f}{g} \\
R=\sqrt{\left(X_{S}-X_{C}\right)^{2}+\left(Y_{S}-Y_{C}\right)^{2}}
\end{array}\right.
$$

$$
\begin{aligned}
& e=2\left(Y_{E}-Y_{S}\right)\left[\left(X_{T}^{2}+Y_{T}^{2}\right)-\left(X_{S}^{2}+Y_{S}^{2}\right)\right]-2\left(Y_{T}-Y_{S}\right)\left[\left(X_{E}^{2}+Y_{E}^{2}\right)-\left(X_{S}^{2}+Y_{S}^{2}\right)\right], \\
& f=2\left(X_{T}-X_{S}\right)\left[\left(X_{E}^{2}+Y_{E}^{2}\right)-\left(X_{S}^{2}+Y_{S}^{2}\right)\right]-2\left(X_{E}-X_{S}\right)\left[\left(X_{T}^{2}+Y_{T}^{2}\right)-\left(X_{S}^{2}+Y_{S}^{2}\right)\right], \\
& g=4\left[\left(X_{T}-X_{S}\right)\left(Y_{E}-Y_{S}\right)-\left(X_{E}-X_{S}\right)\left(Y_{T}-Y_{S}\right)\right] .
\end{aligned}
$$

Except for the location of the cut-in point $S\left(X_{S}, Y_{S}\right)$ and the cut-out point $E\left(X_{E}, Y_{E}\right)$, the curvature of the sliding surface also affects the position of the sliding surface. The factor affecting the curvature is the length of the chord height $M T$ of the arc, that is, the position of the point $T\left(X_{T}\right.$, $\left.Y_{T}\right)$. The arc can be determined by the coordinates of the three points $(S, E$, and $T)$ which are randomly generated. The search range of $S$ and $E$ is on the slope surface line. The maximum value of the $T$ point along the $X$-axis, $X_{\text {Tmax }}$, can be determined as follows.

As shown in Figure 5, the midpoint coordinate $M\left(X_{M}\right.$, $Y_{M}$ ) of the line connecting the cut-in point $S$ and the cut-out point $E$ can be determined. The point $T_{\max }$ must be on the radial line connecting the center $C$ and $M$, and the arc STE must be tangent to the vertical line $S D$, where $S$ is the tangent point. The straight-line $M T$ is expressed as

$$
y=K_{J}\left(x-X_{M}\right)+Y_{M},
$$

where $K_{J}$ is the negative reciprocal of the slope of the straight-line SE. $K_{J}=X_{S}-X_{E} / Y_{E}-Y_{S}$.
When the $T$ point reaches the maximum value along the $X$-axis, the circle center coordinate $C\left(X_{C}, Y_{C}\right)$ corresponding to the arc STE is

$$
\left\{\begin{array}{l}
X_{C}=X_{M}+\frac{Y_{S}-Y_{M}}{K_{J}}, \\
Y_{C}=Y_{S} .
\end{array}\right.
$$

Then, the arc equation is

$$
y=Y_{C}-\sqrt{\left(X_{S}-X_{C}\right)^{2}-\left(x-X_{C}\right)^{2}} .
$$

The coordinates of $T_{\max }$ can be obtained by solving equations (6) and (8):

$$
\begin{aligned}
& X_{T \max }=A_{4}-\sqrt{A_{3}}, \\
& Y_{T \max }=Y_{C}-\sqrt{\left(X_{S}-X_{C}\right)^{2}-\left(X_{T \text { max }}-X_{C}\right)^{2}},
\end{aligned}
$$




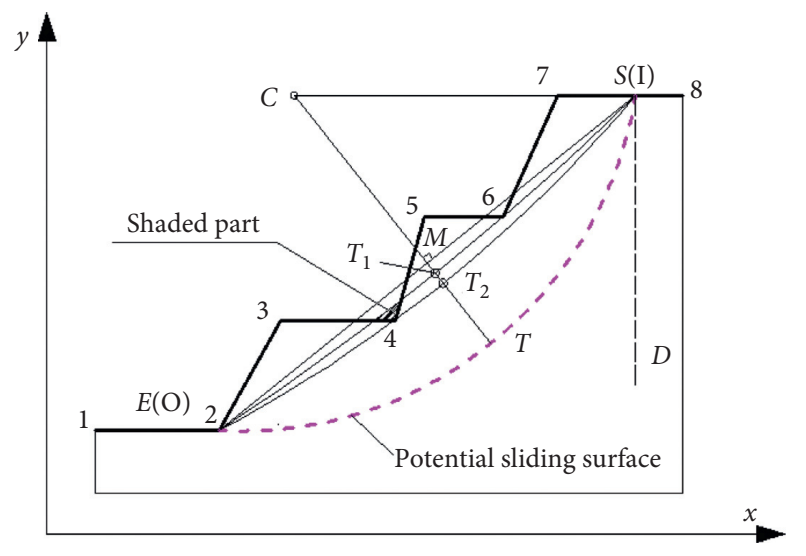

FIGURE 5: Schematic diagram of the point value range in the sliding surface.

where $A_{1}, A_{2}, A_{3}$, and $A_{4}$ are the intermediate parameters as follows:

$$
\begin{aligned}
& A_{4}=\frac{A_{1} * K_{J}+X_{C}}{K_{J}^{2}-1} \\
& A_{3}=\frac{A_{2}^{2}-X_{C}^{2}-A_{1}^{2}}{K_{J}^{2}-1}+\left(\frac{A_{1} * K_{J}+X_{C}}{K_{J}^{2}-1}\right)^{2}, \\
& A_{2}=\left(X_{S}-X_{C}\right)^{2}, \\
& A_{1}=Y_{C}+K_{J} \cdot X_{M}-Y_{M} .
\end{aligned}
$$

Since the geometry of the sliding surface is unlikely to be convex, $X_{T}$ reaches the minimum $X_{T \text { min }}$ when the curvature of the sliding surface is zero.

After determining $X_{T \min }$ and $X_{T \max }$, the search range of $T$ point is defined. $T$ point can be randomly generated in its search range, and then a circular arc sliding surface is determined by STE three points.

For multistep slopes, sometimes unreasonable arcs appear, causing the arcs to cross the boundary, as shown in the shaded part in Figure 5. For this case, the minimum value of the search range of $T$ in the $X$-axis direction needs to be reset. The specific method is as follows:

(1) First, it is necessary to determine whether the control point of each slope line within the range of $\left(X_{E}, X_{S}\right)$ is above the chord line. If all the control points of the slope line in the range of $\left(X_{E}, X_{S}\right)$ are above the chord line, the minimum value of the search range in the $X$ axis direction is $X_{\text {Tmin }}=X_{M}$. If there is a control point below the chord line, the arc is determined by three points of the control point, the cut-in point $S$, and the cut-out point $T$, and the coordinate of the midpoint $T$ of the arc is determined.

(2) Then, it is determined whether other control points are below the arc. If they are below the arc, the arc is determined by the control point, the cut-in point $S$, and the cut-out point $E$, and the coordinates of the midpoint $T$ of the arc are determined. Until it is determined that the control points of the slope line are above the generated new arc, the minimum value of the search range of $T$ in the $X$-axis direction $X_{T \text { min }}$ is finally determined.

The sliding surface of the slope can be determined by three points, and the search range of the three points of the sliding surface $(S, T$, and $E$ ) can be determined according to the procedure mentioned above. Therefore, the analytical formula of a sliding surface can be expressed by

$$
y=f(S, T, E)=f\left(X_{S}, Y_{S}, X_{T}, Y_{T}, X_{E}, Y_{E}\right) .
$$

The coordinates of the three points are randomly generated within their respective search ranges. For example, the search range of the cut-in point $S$ is $\left(X_{7}, X_{8}\right)$, and the search range of the cut-out point $E$ is $\left(X_{2}, X_{3}\right)$. The search range of the point $T\left(X_{T \min }, X_{\text {Tmax }}\right)$ is determined according to the points $S$ and $E$. Rand function is used to generate a group of three random numbers $R_{1}, R_{2}$, and $R_{3}$ in the range of $(0,1)$, and the coordinates of the generated three points $(S$, $E$, and $T$ ) can be expressed as

$$
\begin{aligned}
& \left\{\begin{array}{l}
X_{S}=X_{7}+R_{1}\left(X_{8}-X_{7}\right), \\
Y_{S}=\frac{Y_{8}-Y_{7}}{X_{8}-X_{7}}\left(X_{S}-X_{7}\right)+Y_{7},
\end{array}\right. \\
& \left\{\begin{array}{l}
X_{E}=X_{2}+R_{2}\left(X_{3}-X_{2}\right), \\
Y_{E}=\frac{Y_{3}-Y_{2}}{X_{3}-X_{2}}\left(X_{E}-X_{2}\right)+Y_{2},
\end{array}\right. \\
& \left\{\begin{array}{l}
X_{T}=T_{\min }+R_{3}\left(T_{\max }-T_{\min }\right), \\
Y_{T}=K_{J}\left(X_{T}-X_{M}\right)+Y_{M} .
\end{array}\right.
\end{aligned}
$$

$N$ sets of random numbers are selected to randomly generate $n$ sliding surfaces. The limit equilibrium methods including the Swedish stripe method is used to calculate the stability coefficient of each sliding surface and determine the minimum value of the coefficient. Then, the search range of the cut-in point and the cut-out point is changed to determine the minimum value of the stability coefficients in other regions. Finally, the minimum value of the stability coefficients in all regions is found.

In the proposed method, the position of the sliding surface is controlled by the cut-in point, cut-out point, and arc height. Therefore, it has the advantage that the search variable no longer requires empirical assumption, compared with traditional limit equilibrium methods.

\subsection{Search for the Potential Sliding Surface of a Slope with a} Front Embedded Structural Plane. The cut-out point of the sliding surface of a slope with a front embedded structural plane must be on the front embedded structural plane. Therefore, the sliding surface is composed of STE and OE, as shown in Figure 6. The equation of the linear section $O E$ is expressed as 


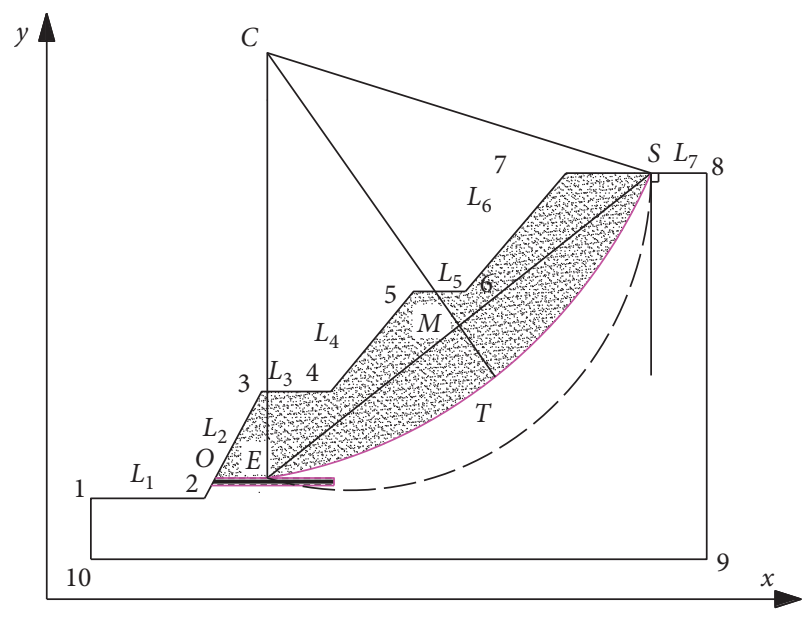

FIGURE 6: Search for potential sliding surface of front embedded structural plane.

$$
y=\frac{Y_{E}-Y_{O}}{X_{E}-X_{O}}\left(x-X_{O}\right)+Y_{O}, \quad X_{O} \leq x \leq X_{E}
$$

Given the three points $S, T$, and $E$, the arc segment $S T E$ is determined according to equations (1) and (2). As mentioned above, the search range of the cut-out point $E$ must be on the front embedded structural plane, and the search range of cutin point $S$ must be on the slope section after the position of the front embedded structural plane, suggesting $x_{s}>x_{e}$. It can be seen that the search range of cut-in point $S$ and cut-out point $E$ is relatively easy to determine, so only the search range of the midpoint $T$ of the arc along the $X$-axis direction needs to be determined. The method of determining the minimum value $X_{\text {Tmin }}$ of the Tpoint in the $X$-direction is the same as the search method for the sliding surface. The maximum value $\left(X_{\text {Tma }}\right)$ of the $T$ point along the $X$-axis direction can be determined as follows.

As shown in Figure 6, the midpoint coordinate $M\left(X_{M}, Y_{M}\right)$ of the line connecting the cut-in point $S$ and the cut-outpoint $E$ can be determined. The point $X_{\text {Tma }}$ must be on the radial line connecting the center $C$ and $M$. Because the sliding surface should not cross the front embedded structural plane (as shown by the dotted line in Figure 6), the arc STE must be tangent to the front embedded structural plane, where $E$ is the tangent point. The straight-line $M T$ is expressed as equation (6), and straight-line $C E$ is expressed as follows:

$$
y=\frac{X_{O}-X_{E}}{Y_{E}-Y_{O}}\left(x-X_{E}\right)+Y_{E}
$$

According to equations (6) and (14), the coordinate of the center of the circle $C$ can be obtained by

$$
\left\{\begin{array}{l}
X_{C}=\frac{K_{J} X_{M}-K_{L} X_{E}+Y_{E}-Y_{M}}{K_{J}-K_{L}}, \\
Y_{C}=\frac{K_{J} K_{L}\left(X_{M}-X_{E}\right)+K_{J} Y_{E}-K_{L} Y_{M}}{K_{J}-K_{L}},
\end{array}\right.
$$

where

$$
K_{L}=\frac{X_{O}-X_{E}}{Y_{E}-Y_{O}}
$$

The arc STE is described by

$$
y=Y_{C}-\sqrt{\left(X_{S}-X_{C}\right)^{2}+\left(Y_{S}-Y_{C}\right)^{2}-\left(x-X_{C}\right)^{2}} .
$$

According to equations (6) and (17), $X_{\text {Tmal }}$ can be obtained by

$$
X_{\text {Tma1 }}=\frac{\sqrt{B^{2}-4 A C}-B}{2 A},
$$

where $A, B$, and $C$ are the intermediate parameters as follows:

$$
\begin{aligned}
& A=K_{J}^{2}+1, \\
& B=2\left[K_{J} Y_{M}-K_{J} Y_{C}-K_{J}^{2}-X_{C}\right], \\
& C=K_{J}^{2} X_{M}^{2}-2 K_{J} X_{M}\left(Y_{M}-Y_{C}\right)-\left(X_{S}-X_{C}\right)^{2}-\left(Y_{S}-Y_{C}\right)^{2} .
\end{aligned}
$$

Because $X_{\text {Tma }}$ should be smaller than $X_{\text {Tmax }}$ and the sliding surface should not cross the front embedded structural plane, therefore

$$
X_{T \text { ma }}=\min \left(X_{T \max }, X_{T \operatorname{mal}}\right) \text {. }
$$

So far, the largest point $X_{T \mathrm{ma}}$ in the $X$-direction of the point $T$ can be obtained. Therefore, the search range of the point $T$ is $x_{T} \in\left(X_{\text {min }}, X_{\text {Tma }}\right)$. The optimization process is the same as the single arc sliding surface in Section 3.2.

3.4. Search for the Potential Sliding Surface of a Slope with a Rear Embedded Structural Plane. The cut-in point of the sliding surface of the rock slope with a rear embedded structural plane must be on the rear embedded structural plane. Therefore, the sliding surface is composed of STE and $I S$, as shown in Figure 7. The equation of the straight-line IS is expressed as

$$
y=\frac{Y_{S}-Y_{I}}{X_{S}-X_{I}}\left(x-X_{I}\right)+Y_{I}, \quad X_{S} \leq x \leq X_{I} .
$$

Given the three points $S, T$, and $E$, the arc segment STE is determined according to equations (1) and (2). As mentioned above, the search range of the cut-in point $S$ must be on the rear embedded structural plane, and the search range of cut-out point $E$ must be on the slope section before the position of the rear embedded structural plane, suggesting $x_{s}>x_{e}$. It can be seen that the search range of cut-in point $S$ and cut-out point $E$ is relatively easy to determine, so only the search range of the midpoint $T$ of the arc along the $X$-axis direction needs to be determined. The method of determining the minimum value $X_{\text {Tmin }}$ of the T point in the $X$ direction is the same as the search method for the sliding surface. The maximum value $\left(X_{\text {Tma }}\right)$ of the $T$ point along the $X$-axis direction can be determined as follows. 


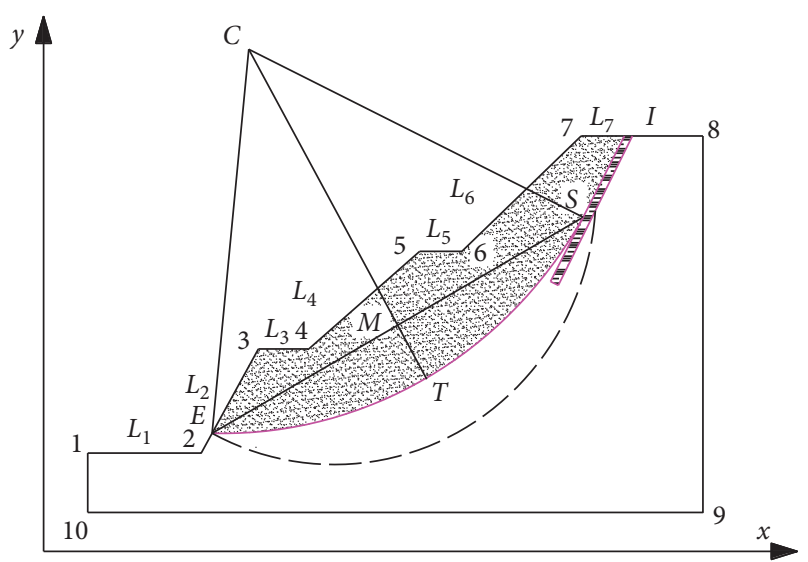

FIgURE 7: Search for potential sliding surface of rear embedded structural plane.

As shown in Figure 7, the midpoint coordinate $M\left(X_{M}\right.$, $\left.Y_{M}\right)$ of the line connecting the cut-in point $S$ and the cut-out point $E$ can be determined. The point $X_{\text {Tma }}$ must be on the radial line connecting the center $C$ and $M$. Because the sliding surface should not cross the rear embedded structural plane (as shown by the dotted line in Figure 7), the arc STE must be tangent to the rear embedded structural plane, where $S$ is the tangent point. The straight-line $M T$ is expressed as equation (6), and straight-line CS is expressed as follows:

$$
y=\frac{X_{I}-X_{S}}{Y_{S}-Y_{I}}\left(x-X_{S}\right)+Y_{S} .
$$

According to equations (6) and (22), the coordinate of the center of the circle $C$ can be obtained by

$$
\left\{\begin{array}{l}
X_{C}=\frac{K_{J} X_{M}-K_{L} X_{S}+Y_{S}-Y_{M}}{K_{J}-K_{L}}, \\
Y_{C}=\frac{K_{J} K_{L}\left(X_{M}-X_{S}\right)+K_{J} Y_{S}-K_{L} Y_{M}}{K_{J}-K_{L}},
\end{array}\right.
$$

where

$$
K_{L}=\frac{X_{I}-X_{S}}{Y_{S}-Y_{I}} .
$$

The arc STE is described by

$$
y=Y_{C}-\sqrt{\left(X_{S}-X_{C}\right)^{2}+\left(Y_{S}-Y_{C}\right)^{2}-\left(x-X_{C}\right)^{2}} .
$$

According to equations (6) and (25), $X_{\text {Tma1 }}$ can be obtained by

$$
X_{\text {Tma1 }}=\frac{\sqrt{B^{2}-4 A C}-B}{2 A},
$$

where $A, B$, and $C$ are the intermediate parameters as follows:

$$
\begin{aligned}
& A=K_{J}^{2}+1, \\
& B=2\left[K_{J} Y_{M}-K_{J} Y_{C}-K_{J}^{2}-X_{C}\right], \\
& C=K_{J}^{2} X_{M}^{2}-2 K_{J} X_{M}\left(Y_{M}-Y_{C}\right)-\left(X_{S}-X_{C}\right)^{2}-\left(Y_{S}-Y_{C}\right)^{2} .
\end{aligned}
$$

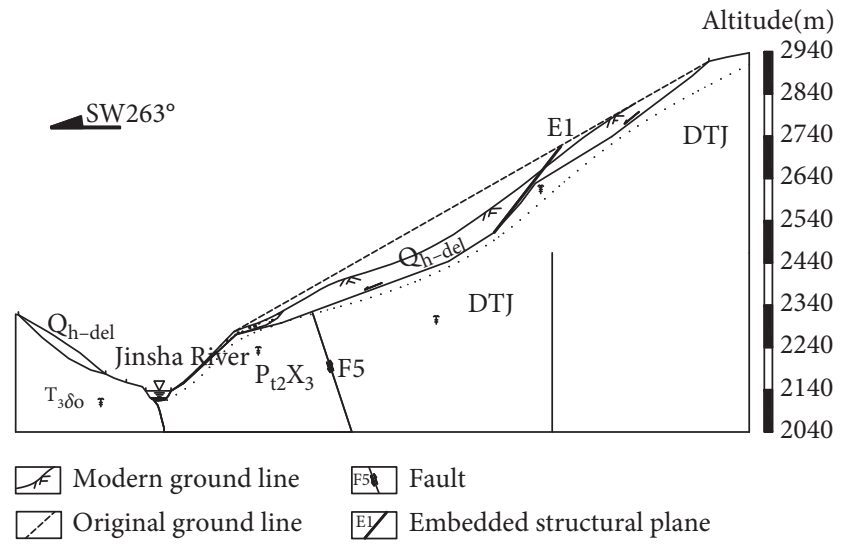

FIgURE 8: Engineering geological section of Zongrong village landslide.

Because $X_{\text {Tma }}$ should be smaller than $X_{\text {Tmax }}$ and the sliding surface should not cross the rear embedded structural plane, therefore

$$
X_{\text {Tma }}=\min \left(X_{T \max }, X_{T \operatorname{mal}}\right) .
$$

So far, the largest point $X_{\text {Tma }}$ in the $X$-direction of the point $T$ can be obtained. Therefore, the search range of the point $T$ is $x_{\mathrm{T}} \in\left(X_{\mathrm{min}}, X_{\mathrm{Tma}}\right)$. The optimization process is the same as the single arc sliding surface in Section 3.2.

\section{Case Analysis}

In order to verify the applicability of this method, a high and steep rock slope in the Tibet Plateau, the Zongrong landslide, is taken as a case study. The Zongrong landslide is located at $82 \mathrm{~km}$ upstream of Jinsha River from the Benzilan town. The left bank of Jinsha River is high and erodes the foot of slope on the left side of the river. Figure 8 shows the engineering geological section of the landslide. The landslide has a bowlshaped geometry with an elevation of $2145 \mathrm{~m}$ at the front edge and $2920 \mathrm{~m}$ at the rear edge. There are four kinds of strata exposed in the study area including (1) $Q_{h-\text { del }} \mathrm{Ho}$ locene landslide accumulation; (2) $T_{3} \delta o$ quartz diorite; (3) $P_{t 2} X^{3}$ middle Proterozoic mica schist; and (4) DTJ Paleozoic ophiolite. The ophiolite rock exposed at the head scarp of the slope is strongly fractured, which is in cataclastic or loose structure. The typical joint sets include (1) NW340 $<50-52^{\circ}$, (2) $\mathrm{NE} 13^{\circ}<47^{\circ}$, and (3) NW295 $<82^{\circ}$. Among them, the joint plane $\mathrm{NW} 340^{\circ}<50-52^{\circ}$ is the main controlling structural plane ( $E_{1}$ in Figure 8$)$, and the slip zone scratch on the structural plane is obvious, which constitute the rear embedded structural plane of the slope and become a part of the sliding surface of the rock landslide.

The transfer coefficient method and the Sarma method are used to calculate the slope stability, both considering the adverse geological conditions such as rainfall infiltration, groundwater effect, earthquake action, and embedded structural plane. The potential slid surface and stability coefficient of the Zongrong slope are obtained by the finite random tracking method considering the embedded structural plane, as shown in Figure 9 and Table 1. 


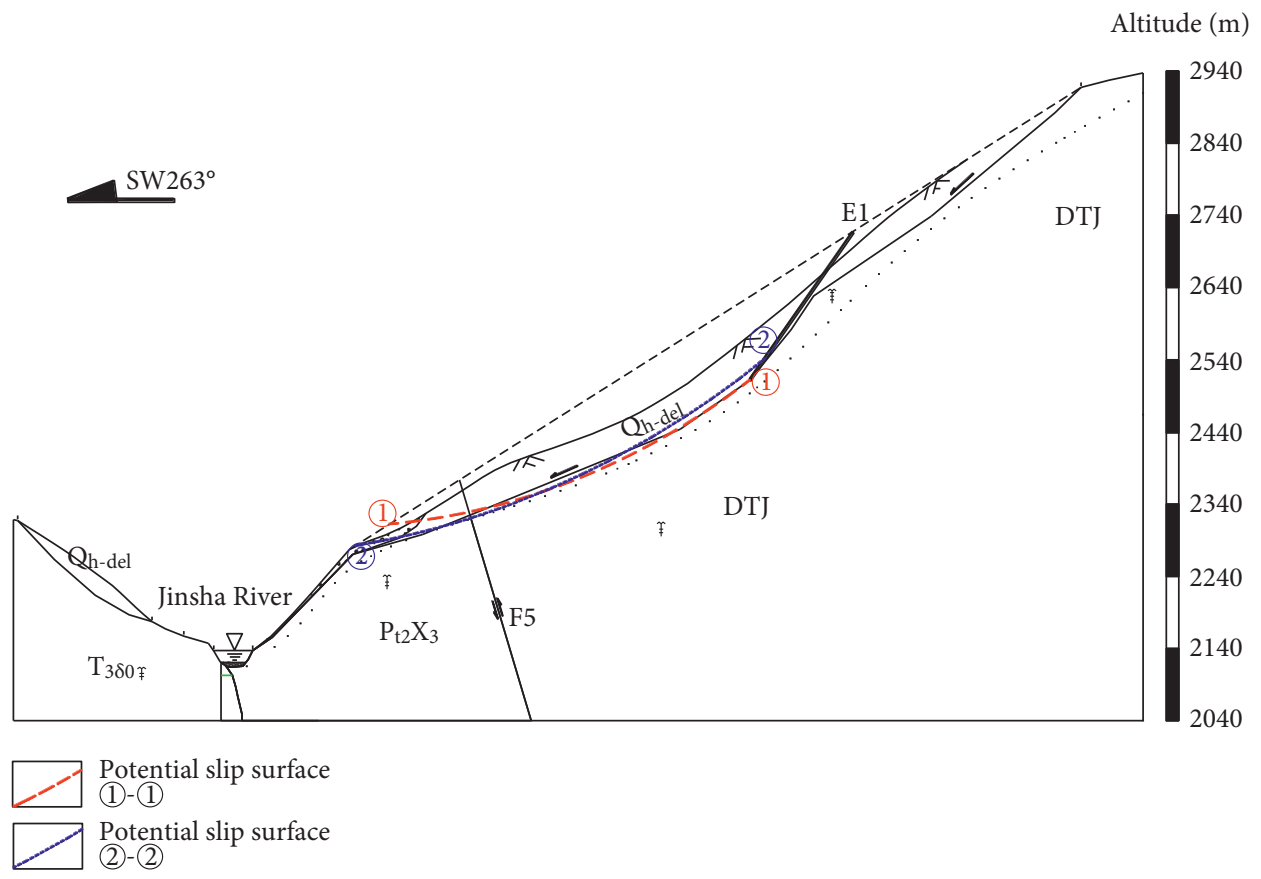

FIGURE 9: Potential sliding surface of Zongrong village landslide obtained by searching result.

Table 1: Stability coefficient of the Zongrong landslide under different environmental conditions.

\begin{tabular}{lcccr}
\hline \multirow{2}{*}{ Method } & \multicolumn{3}{c}{ Working conditions } \\
& Natural state & Rainfall saturation & Earthquake $(0.4 \mathrm{~g})$ & Earthquake $(0.6 \mathrm{~g})$ \\
\hline Transfer coefficient method & 1.34 & 0.62 & 1.07 & 0.97 \\
Sarma method & 1.27 & 0.67 & 1.04 & 0.95 \\
\hline
\end{tabular}

According to Table 1, slope failure could occur under environmental conditions such as rainfall and earthquake. Under different conditions, the position of the potential sliding surface is different, but the embedded structural plane $E_{1}$ is a part of the sliding surface and is the main control structural plane. The potential sliding surface is cut out from the high position of the front edge of the slope, as shown in Figure 9. Among them, the combination of (1)-(1) $+E_{1}$ is the potential sliding surface under the condition of rainfall and water saturation, and the combination of (2)-(2) $+E_{1}$ is the potential sliding surface of landslide under strong earthquake.

\section{Conclusions}

In the rock slope, the embedded structural plane will have an impact on the stability of the slope. Considering the existence of the embedded structural plane, the search method for the potential sliding surface of the rock slope is studied. The potential sliding surface search method suitable for this kind of project is proposed, which provides a theoretical method for rock slope stability analysis and evaluation. The main conclusions are as follows:

(1) According to the location of the embedded structural plane in the rock slope, the embedded structural plane in rock slope is divided into two forms: front embedded and rear embedded structural planes. The influence of an embedded structural plane on the potential sliding surface of the rock slope was analyzed. The results show that the embedded structural plane is part of the potential sliding surface of the slope. When searching for the potential sliding surface of such projects, the influence of the embedded structural plane should be considered.

(2) Aiming at two kinds of rock slopes with embedded structural plane, combined with the finite random tracking method, a potential sliding surface search method suitable for rock slopes with embedded structural plane was proposed. This method takes into account the influence of the embedded structural plane, improves the selection method of the search variable of the sliding surface, and controls the position of the sliding surface through the cut-in point, the cut-out point, and the arc height. Therefore, it has the advantage that the search variable no longer needs empirical assumption.

(3) The reliability of the method is verified through a case study. The results show that the proposed method could accurately obtain the potential sliding surface of the rock slope with embedded structural plane, which provides a theoretical basis for slope stability analysis. 


\section{Data Availability}

The data used to support the findings of this study are available from the corresponding author upon request.

\section{Conflicts of Interest}

The authors declare that they have no conflicts of interest.

\section{Acknowledgments}

The financial support for this work was provided by the National Key Research and Development Program of China (Grant No. 2018YFC1505001), which is gratefully acknowledged.

\section{References}

[1] K. Kang, A. Ponomarev, O. Zerkal, S. Y. Huang, and Q. G. Lin, "Shallow landslide susceptibility mapping in sochi ski-jump area using GIS and numerical modelling," ISPRS International Journal of Geo-Information, vol. 8, no. 3, Article ID 148, 2019.

[2] L. X. Jin and Q. X. Feng, "Improved radial movement optimization to determine the critical failure surface for slope stability analysis," Environmental Earth Sciences, vol. 77, no. 16, Article ID 564, 2018.

[3] H. Pei, S. Zhang, L. Borana, Y. Zhao, and J. Yin, "Slope stability analysis based on real-time displacement measurements," Measurement, vol. 131, pp. 686-693, 2019.

[4] H. B. Xue, F. N. Dang, X. T. Yin, W. H. Ding, and C. Yang, "Nonproportional correlative reduction finite element method for slope strength parameters," Mathematical Problems in Engineering, vol. 2016, Article ID 2725354, 10 pages, 2016.

[5] S. C. Wu, L. Q. Han, Z. Q. Cheng, X. Q. Zhang, and H. Y. Cheng, "Study on the limit equilibrium slice method considering characteristics of inter-slice normal forces distribution: the improved Spencer method," Environmental Earth Sciences, vol. 78, no. 20, Article ID 611, 2019.

[6] X. Diao, K. Wu, D. Zhou, J. Wang, Z. Duan, and Z. Yu, "Combining subsidence theory and slope stability analysis method for building damage assessment in mountainous mining subsidence regions," PLoS One, vol. 14, no. 2, Article ID e0210021, 2019.

[7] M. W. Guo, S. J. Liu, S. D. Yin, and S. L. Wang, "Stability analysis of the Zhangmu multi-layer landslide using the vector sum method in Tibet, China," Bulletin of Engineering Geology and the Environment, vol. 78, no. 9, pp. 4187-4200, 2019.

[8] X. P. Zhou, X. D. Zhao, L. N. Y. Wong, and H. Cheng, "A modified Sarma method for stability analysis of layered slopes," Bulletin of Engineering Geology and the Environment, vol. 78, no. 3, pp. 1893-1909, 2019.

[9] Y. Tang, H. Lin, Y. Wang, and Y. Zhao, "Rock slope stability analysis considering the effect of locked section," Bulletin of Engineering Geology and the Environment, vol. 80, no. 9, pp. 7241-7251, 2021.

[10] Y. Chen, H. Lin, R. Cao, and C. Zhang, "Slope stability analysis considering different contributions of shear strength parameters," International Journal of Geomechanics, vol. 24, no. 3, Article ID 04020265, 2021.

[11] H. H. Mo and S. Y. Liu, "The application of the pattern search method for slope stability analysis," Journal of South China University of Technology, vol. 28, no. 2, pp. 42-46, 2000.
[12] A. Kremen and Y. Tsompanakis, "Application of dynamic programming to evaluate the slope stability of a vertical extension to a balefill," Waste Management \& Research: The Journal for a Sustainable Circular Economy, vol. 28, no. 4, pp. 373-382, 2010.

[13] J. Chen, J. H. Yin, and C. F. Lee, "The use of an SQP algorithm in slope stability analysis," Communications in Numerical Methods in Engineering, vol. 21, no. 1, pp. 23-37, 2005.

[14] E. Boutrup and C. W. Lovell, "Searching techniques in slope stability analysis," Engineering Geology, vol. 16, no. 1-2, pp. 51-61, 1980.

[15] M. Shinoda and Y. Miyata, "PSO-based stability analysis of unreinforced and reinforced soil slopes using non-circular slip surface," Acta Geotechnica, vol. 14, no. 3, pp. 907-919, 2019.

[16] A. Johari and S. Mousavi, "An analytical probabilistic analysis of slopes based on limit equilibrium methods," Bulletin of Engineering Geology and the Environment, vol. 78, no. 6, pp. 4333-4347, 2019.

[17] Y. W. Tun, M. A. Llano-Serna, D. M. Pedroso, and A. Scheuermann, "Multimodal reliability analysis of 3D slopes with a genetic algorithm," Acta Geotechnica, vol. 14, no. 1, pp. 207-223, 2019.

[18] Y. K. Wan, Y. F. Gao, and F. Zhang, "Stability analysis of three-dimensional slopes considering the earthquake force direction," Mathematical Problems in Engineering, vol. 2018, Article ID 2381370, 10 pages, 2018.

[19] A. J. Yao and T. H. Xue, Evaluation Method and Engineering Practice of Complex Slope Stability, Science Press, Beijing, China, 2008. 